\title{
Normalizacja wykrywania i oceny powierzchniowych niezgodności spawalniczych
}

\section{Standardization of detection and evaluation of welding imperfections}

\section{Streszczenie}

Badania nieniszczące dostarczają informacji o jakości złączy spawanych bez zmiany ich przydatności użytkowej. Normy, definiujące metody przeprowadzania badań nieniszczących, obejmują bardzo szeroki zakres zagadnień. W pracy omówiono podstawowe grupy norm, określające istotne elementy procedur badań nieniszczących złączy spawanych w zakresie wykrywania i oceny niezgodności powierzchniowych. Analiza uzyskanych wskazań pozwala na wyznaczenie poziomów akceptacji i poziomu jakości kontrolowanego złącza.

\section{Wstęp}

Podstawową metodą łączenia, stosowaną w konstrukcjach metalowych, jest spawanie. W złączach spawanych mogą występować niezgodności wynikające z przebiegu procesu. Metody badań nieniszczących umożliwiają, z określonym prawdopodobieństwem, wykrywanie zarówno powierzchniowych, jak i wewnętrznych niezgodności w złączach spawanych. Zasady stosowania badań nieniszczących złączy spawanych metali zawarte są w normie PN-EN ISO17635 [3], która jest normą podstawową (zastąpiła normę PN-EN 12062). Podaje ona zasady wyboru metod badań nieniszczących oraz oceny ich wyników w zależności od metody spawania, materiału podstawowego i dodatkowego, stanu obróbki, rodzaju złącza i spoin oraz ich wymiarów, ukształtowania elementu, założonego poziomu jakości i spodziewanych

Dr inż. Lesław Sozański, mgr inż. Paweł Sokołowski - Politechnika Wrocławska.
Abstract

Non destructive testing provides useful information about the quality of welds without changing any of their properties. The standards for non-destructive testing (NDT) methods include a lot of different issues. This paper discusses an important group of standards which defines the essential elements of non-destructive weld examination procedures. These procedures are useful to detect and evaluate of welding defects located at the surface of joined elements. The analysis of received data allows determining the acceptance levels and the quality of the controlled weld.

rodzajów niezgodności spawalniczych oraz ich usytuowania. W normie wprowadzono też wymagania dotyczące personelu wykonującego badania (wg PN-EN 473 [4] lub EN ISO 9712 [5]).

Norma ISO 17835 [3] zaleca do wykrywania, powierzchniowych niezgodności spawalniczych, we wszystkich rodzajach złączy spawanych, kontrolę wizualną w połączeniu z innymi metodami: penetracyjną, magnetyczno-proszkową oraz prądów wirowych dla różnych materiałów podstawowych (stale ferrytyczne, austenityczne, aluminium, nikiel, miedź i tytan). Zdefiniowane poziomy akceptacji są przeznaczone przede wszystkim do zastosowania w badaniach produkcyjnych.

\section{Badania wizualne}

Pojęcie badań wizualnych obejmuje wykrywanie i ocenę cech jakościowych złącza wyłączeniu za pomocą ludzkiego oka. Podczas gdy wszystkie inne metody badań nieniszczących dostarczają informacji, które wymagają dodatkowej interpretacji, to w przypadku badań 


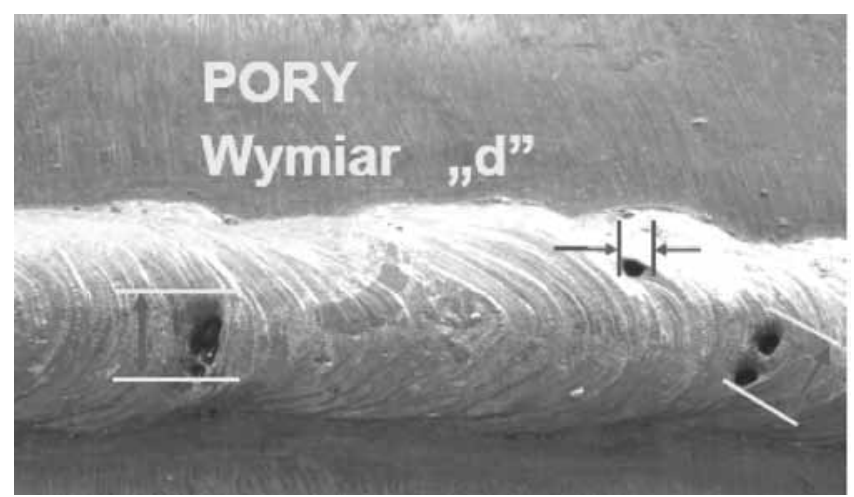

Rys. 1. Wymiar charakterystyczny „d” porów [1]

Fig. 1. Specific dimension „d” for pores [1]

Tablica I. Poziomy jakości złączy określane na podstawie badań wizualnych wg PN-EN ISO 17835 [3]

Table I. Quality level determination by visual testing acc. to PN-EN ISO 17835 [3]

\begin{tabular}{|c|c|c|}
\hline $\begin{array}{l}\text { Poziomy jakości } \\
\text { wg ISO } 5817 \\
\text { oraz ISO } 10042\end{array}$ & $\begin{array}{c}\text { Technika - I klasa } \\
\text { badania } \\
\text { wg ISO } 17637\end{array}$ & $\begin{array}{l}\text { Poziomy } \\
\text { akceptacji a) }\end{array}$ \\
\hline$B$ & \multirow{3}{*}{ Klasy nie określono } & B \\
\hline $\mathrm{C}$ & & $\mathrm{C}$ \\
\hline $\mathrm{D}$ & & $\mathrm{D}$ \\
\hline
\end{tabular}

wizualnych można bezpośrednio obserwować takie niezgodności, jak: nieciągłości materiałowe, odchylenia od wymiarów czy jakości powierzchni obrobionej. Przyjęto dwie podstawowe techniki badań wizualnych: badania wizualne bezpośrednie i badania wizualne zdalne. Pojęcia te są zdefiniowane w PN-EN 13018 [6], są oparte na różnicy w przebiegu ścieżki optycznej pomiędzy okiem obserwatora a powierzchnią badaną.

W normie PN-EN ISO 17637 [7] podano wymagania dotyczące badań wizualnych złączy spawanych metali. Przeprowadza się je najczęściej na złączach gotowych, jednak w przypadkach uzasadnionych wymogami norm wyrobu lub ustaleniami między stronami umowy można wykonać je w innych fazach procesu spawania. Podstawową normą opisującą niezgodności spawalnicze jest PN-EN ISO 6520-1 [8]. Norma ISO 17835 [3] w tablicy A.1 zawiera zasady określania poziomów jakości złączy, oparte na kryteriach zawartych w PN-EN ISO 5817 [9] (tabl. I), a na rysunku 1 pokazano przykładowo wymiary charakterystyczne porów.

\section{Badania penetracyjne}

W badaniach penetracyjnych wykorzystuje się zjawiska kapilarne w nieciągłościach na kontrolowanej powierzchni. Penetrant wnika w otwarte szczeliny powierzchniowe, a po usunięciu jego nadmiaru
Tablica II. Badania penetracyjne - poziomy akceptacji [3]

Table II. Penetration testing - acceptance levels [3]

\begin{tabular}{|c|c|c|}
\hline $\begin{array}{c}\text { Poziomy jakości } \\
\text { wg ISO 5817 } \\
\text { oraz ISO 10042 }\end{array}$ & $\begin{array}{c}\text { Technika - I klasa } \\
\text { badania wg } \\
\text { ISO 3452-1 }\end{array}$ & $\begin{array}{c}\text { Poziomy akceptacji } \\
\text { wg ISO 23277 }\end{array}$ \\
\cline { 1 - 1 } B & \multirow{3}{*}{ Klasy nie określono } & $2 x$ \\
\cline { 1 - 1 } C & & $2 x$ \\
\cline { 1 - 1 } D & & $3 x$ \\
\hline
\end{tabular}

Poziomy akceptacji 2 i 3 mogą być ustalone z oznaczeniem wstępnym X, co oznacza, że wszystkie wykryte wskazania liniowe powinny być oceniane wg poziomu 1. Jednak prawdopodobieństwo wykrycia wskazań mniejszych od podanych przez początkowy poziom akceptacji może być niewielkiego.

i naniesieniu wywoływacza zabarwia go w miejscach nieciągłości tworząc mierzalne wskazania. Ogólne zasady badań penetracyjnych podano w PN-EN 571-1 [11]. W normie tej ustalono zasady przygotowania badanej powierzchni, wymagania stawiane środkom wykrywającym i sposobom ich użycia, a także zapis i interpretację uzyskanych wyników [1]. W normie wprowadzono postanowienia zawarte, m.in., w powołaniach normatywnych dotyczących personelu wykonującego badania (PN-EN 473 [7]), badań materiałów penetracyjnych (PN-EN ISO 3452-2 [12]), próbek odniesienia (PN-EN ISO 345-3 [13], wyposażenia (PN-EN ISO 345-4 [14]), zasad badań powyżej $50^{\circ} \mathrm{C}$ (EN ISO 3452-5:2008 [15] i poniżej $10^{\circ} \mathrm{C}$ (EN ISO 3452-6:2008 [16]) oraz warunków obserwacji (EN ISO 3059 [17]). Dla badań metodą penetracyjną opracowano specjalną normę terminologiczną PN-EN ISO 12706:2003 [18].

W normie PN-EN ISO 17835 [3] zaleca się metodę penetracyjną, w połączeniu z kontrolą wizualną, do wykrywania dostępnych, powierzchniowych niezgodności spawalniczych złączy ze stali austenitycznych, stopów aluminium, miedzi, tytanu i niklu.

W jej załączniku A-3 podano w tablicy 3A zależność między poziomami jakości a techniką badań i poziomami akceptacji wg tablicy II.

Poziomy akceptacji (tabl. III), podane w normie, określono na podstawie możliwości wykrycia niezgodności spawalniczych przy zastosowaniu technik badań podanych w PN-EN ISO 3452-1 [12].

Tablica III. Poziomy akceptacji wskazań [19]; wymiary w mm Table III. Results acceptance levels [19]; dimensions in $\mathrm{mm}$

\begin{tabular}{|c|c|c|c|}
\hline \multirow{2}{*}{ Rodzaj wskazania } & \multicolumn{3}{|c|}{ Poziom akceptacji a) } \\
\cline { 2 - 4 } & 1 & 2 & 3 \\
\hline $\begin{array}{c}\text { Wskazanie liniowe I } \\
\text { - długość wskazania, } \mathrm{mm}\end{array}$ & $\mathrm{I} \leq 1,5$ & $\mathrm{I} \leq 3$ & $\mathrm{I} \leq 6$ \\
\hline $\begin{array}{c}\text { Wskazanie nieliniowe } \mathrm{d} \\
\text { - wymiar większej osi, } \mathrm{mm}\end{array}$ & $\mathrm{I} \leq 2$ & $\mathrm{I} \leq 3$ & $\mathrm{I} \leq 4$ \\
\hline
\end{tabular}

a) Poziomy akceptacji 2 i 3 moga być ustalone z oznaczeniem wstępnym X, co oznacza, że wszystkie wykryte wskazania liniowe powinny być oceniane wg poziomu 1. Jednak prawdopodobieństwo wykrycia wskazań mniejszych od podanych przez początkowy poziom akceptacji może być niskie. 


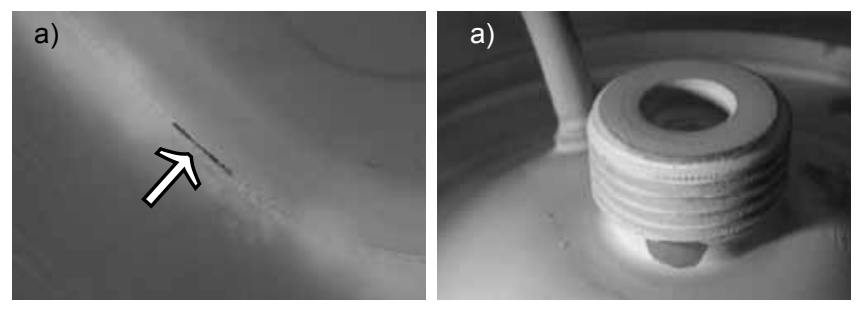

Rys. 2. Defektogram: a) wskazanie liniowe, b) wskazanie nieliniowe [1] Fig. 2. Defectogram: a) linear result, b) non-linear result [1]

\section{Badania magnetyczno-proszkowe}

W badaniach magnetyczno-proszkowych wykorzystuje się zjawisko gromadzenia się proszku ferromagnetycznego w miejscu rozproszonego przez nieciągłości powierzchniowe pola magnetycznego. Ogólne przepisy badań magnetyczno-proszkowych [2] są zawarte w normie PN-EN ISO 9934-1 [20]. W normie tej ustalono zasady przygotowania badanej powierzch$\mathrm{ni}$, stosowane techniki magnesowania, wymagania stawiane środkom wykrywającym rozproszone pole i sposobom ich użycia, a także zapis i interpretacjom uzyskanych wyników. W normie wprowadzono postanowienia zawarte, m.in., w powołaniach normatywnych dotyczących personelu wykonującego badania (PN-EN 473 [4]), wyposażenia (PN-EN ISO 9934-2,3 [21, 22]) i warunków obserwacji (PN-EN ISO 3059 [17]).

Norma PN-EN ISO 17635 [3] zaleca metodę magnetyczno-proszkową, w połączeniu z kontrolą wizualną, do wykrywania dostępnych, powierzchniowych niezgodności spawalniczych we wszystkich rodzajach złączy spawanych ze stali ferrytycznych. W jej

Tablica IV. Badania magnetyczno-proszkowe [3]

Table IV. Magnetic particle inspection [3]

\begin{tabular}{|c|c|c|}
\hline $\begin{array}{c}\text { Poziom jakości } \\
\text { wg PN-EN } \\
\text { ISO } 5817\end{array}$ & $\begin{array}{c}\text { Technika i klasa } \\
\text { badania wg PN-EN } \\
\text { ISO 17638 }\end{array}$ & $\begin{array}{c}\text { Poziomy akceptacji } \\
\text { wg PN-EN ISO 23278 }\end{array}$ \\
\hline B & \multirow{3}{*}{ Klasy nie określono } & $2 \mathrm{x}$ \\
& & $2 \mathrm{x}$ \\
\hline $\mathrm{C}$ & & $3 \mathrm{x}$ \\
\hline
\end{tabular}

Poziomy akceptacji 2 i 3 mogą być ustalone z oznaczeniem wstępnym X, co oznacza, że wszystkie wykryte wskazania liniowe powinny być oceniane wg poziomu 1. Jednak prawdopodobieństwo wykrycia wskazań mniejszych od podanych przez początkowy poziom akceptacji może być niewielkie.

Tablica V. Poziomy akceptacji wskazań [24]

Table V. Results acceptance levels [24]

\begin{tabular}{|c|c|c|c|}
\hline \multirow{2}{*}{ Rodzaj wskazania } & \multicolumn{3}{|c|}{ Poziom akceptacji $\left.{ }^{1}\right)$} \\
\cline { 2 - 4 } & 1 & 2 & 3 \\
\hline Wskazanie liniowe I - długość wskazania, $\mathrm{mm}$ & $\mathrm{I} \leq 1,5$ & $\mathrm{I} \leq 3$ & $\mathrm{I} \leq 6$ \\
\hline $\begin{array}{c}\text { Wskazanie nieliniowe d - wymiar większej } \\
\text { osi, } \mathrm{mm}\end{array}$ & $\mathrm{I} \leq 2$ & $\mathrm{I} \leq 3$ & $\mathrm{I} \leq 4$ \\
\hline
\end{tabular}

Poziomy akceptacji 2 i 3 mogą być ustalone z oznaczeniem wstępnym „X”, co oznacza, że wszystkie wykryte wskazania liniowe powinny być oceniane wg poziomu 1. Jednak prawdopodobieństwo wykrycia wskazań mniejszych od podanych przez początkowy poziom akceptacji może być niskie

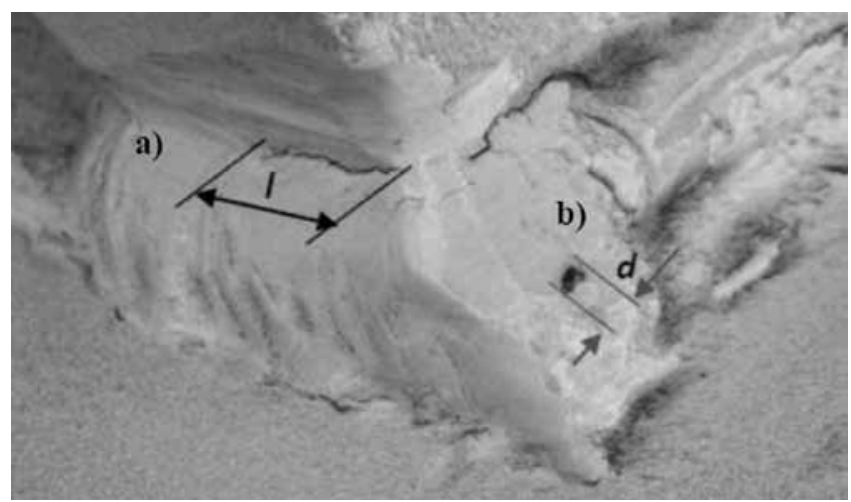

Rys. 3. Defektogram proszkowy: a - wskazanie liniowe, b - wskazanie nieliniowe [2]

Fig. 3. Particle defectogram: $a$ - linear result, $b$ - non-linear result [2]

załączniku A-3 podano w tablicy 3A zależność między poziomami jakości wg PN-EN ISO 5817 [9] a techniką badań wg PN-EN ISO 17638 [23] i poziomami akceptacji wg PN-EN ISO 23278 [24] (tabl. IV). Poziomy akceptacji zdefiniowano w zależności od rodzaju i wielkości wskazań (tabl. V).

Dla badań metodą magnetyczno-proszkową opracowano specjalną normę terminologiczną PN-EN 1330-7, w której zdefiniowano terminy stosowane w tych badaniach oraz zamieszczono alfabetyczny indeks krzyżowy w języku polskim [25].

Norma badań PN-EN ISO 17638 [23] zaleca bardzo precyzyjnie metodologię przeprowadzenia kontroli złączy spawanych wraz z rysunkami i wzorami obliczeń układów geometrycznych i danych elektrycznych istotnych dla uzyskania odpowiedniego dla kształtu kontrolowanego elementu pola magnetycznego. Przywołuje też normy ogólne dotyczące środków wykrywających (PN-EN ISO 9934-2 [26]) oraz stosowanej aparatury (PN-EN ISO 9934-3 [27]).

\section{Prądy wirowe}

W metodzie prądów wirowych (ET) wykorzystywane jest zjawisko indukcji magnetycznej. Analizując pole magnetyczne wzbudzonych prądów wirowych, płynących na powierzchni badanego materiału, możemy wykrywać ewentualne nieciągłości materiałowe, a także zmiany strukturalne. Złącza spawane są trudne do kontroli tą metodą. W przypadku spoin wykonywanych $w$ procesach automatycznych, zapewniających gładkie lico, zastosowanie prądów wirowych jest w pełni uzasadnione i często stosowane (np. przy produkcji rur ze szwem). Jednak nierównomierność lica czy łuska, charakterystyczne dla spawania elektrodą otuloną czy nawet w gazach ochronnych, jest poważnym utrudnieniem $w$ interpretacji otrzymywanych wyników. Podobnie zmiany strukturalne w SWC mogą powodować obniżoną wykrywalność drobnych pęknięć czy przyklejeń w strefie wtopienia. Jednak jej podstawowe zalety - metoda praktycznie bezkontaktowa 
Tablica VI. Klasy jakości - ocena metodą prądów wirowych [3] Table VI. Quality levels - Eddy current method [3]

\begin{tabular}{|c|c|c|}
\hline $\begin{array}{c}\text { Poziom jakości } \\
\text { wg ISO 5817 } \\
\text { oraz ISO 10042 }\end{array}$ & $\begin{array}{c}\text { Technika i klasa } \\
\text { badania } \\
\text { wg ISO 17643 }\end{array}$ & Poziomy akceptacji \\
\cline { 1 - 2 } B & Klasy nie określono & $\begin{array}{c}\text { Uzgodnione między } \\
\text { stronami umowy }\end{array}$ \\
\cline { 1 - 1 } C & D &
\end{tabular}

z możliwością badania przez pokrycia lakiernicze, powoduje jej szybki rozwój. Zakres normalizacji metody prądów wirowych jest niewielki. W normie PN-EN ISO 17635 [3] w tabeli A.4 podano jedynie normę ogólną ISO 17643 [28], a poziomy akceptacji muszą być uzgodnione między stronami umowy (tabl. VI).

\section{Podsumowanie}

Zadaniem badań nieniszczących w analizowanym zakresie jest wykrycie niezgodności powierzchniowych oraz określenie ich wielkości, położenia i nasilenia. Europejski system norm i zaleceń (normy podstawowe, normy badań i normy wyrobu) pozwala na stosunkowo łatwe opracowanie procedur i instrukcji kontrolnych w standardowych przypadkach badania złączy spawanych konstrukcji metalowych. Ustalenia normalizacyjne przewidziane są do wykorzystania w kontroli produkcyjnej. W zasadzie tylko normy badań sa pomocne w badaniach eksploatacyjnych. Badania wizualne, penetracyjne i magnetyczno-proszkowe stanowią podstawowe techniki stosowane do wykrywania niezgodności spawalniczych na powierzchniach dostępnych. W innych przypadkach (np. niedostępne strefy graniowe) trzeba stosować metody ultradźwiękowe lub radiologiczne. Oszacowanie niepewności badań oraz odpowiednia interpretacja uzyskanych wyników pozwalają na uzyskanie miarodajnego obrazu jakości kontrolowanego złącza.

\section{Literatura}

[1] Sozański L., Sullik P.: Analyza normalizace zkouśeni svaru kapilarni metodou. 42. Mezinárodní Konference a Výstava NDT Techniky: DEFEKTOSKOPIE 2012. Sborník příspěvků, Sec u Chrudimi, Czech Republic.

[2] Sozański L.: Wybrane normy badań magnetyczno-proszkowych złączy spawanych. Przegląd Spawalnictwa. nr 10/2012.

[3] PN-EN ISO 17635:2010. Badania nieniszczące złączy spawanych. Zasady ogólne dotyczące metali.

[4] PN-EN 473: 2008. Badania nieniszczące - Kwalifikacja i certyfikacja personelu.

[5] PN-EN ISO 9712:2005. Badania nieniszczące - Kwalifikacja i certyfikacja personelu.

[6] PN-EN 13018:2004. Badania nieniszczące. Badania wizualne. Zasady ogólne.

[7] PN-EN ISO 17637:2011. Badania nieniszczące złączy spawanych-Badania wizualne złączy spawanych.

[8] PN-EN ISO 6520-1:2007. Spawanie i procesy pokrewne. Klasyfikacja geometrycznych niezgodności spawalniczych w metalach, Część 1: Spawanie.

[9] PN-EN ISO 5817:2010. Badania nieniszczące złączy spawanych. Zasady ogólne dotyczące metali.

[10] PN-EN ISO 10042:2008. Spawanie - Złącza spawane łukowo $w$ aluminium i jego stopach - Poziomy jakości dla niezgodności spawalniczych.

[11] PN-EN 571-1:1999. Badania nieniszczące - Badania penetracyjne. Zasady ogólne.

[12] PN-EN ISO 3452-2:2006. Badania nieniszczące-Badania penetracyjne-Cz. 2 Badania materiałów penetracyjnych.

[13] PN-EN ISO 3452-3:2001. Badania nieniszczące - Badania penetracyjne. Część 3: Próbki odniesienia.

[14] PN-EN ISO 345-4:2001. Badania nieniszczące - Badania penetracyjne. Część 4: Wyposażenie.
[15] EN ISO 3452-5:2008. Non-destructive testing - Penetrant testing - Part 5: Penetrant testing at temperatures higher than $500 \mathrm{C}$.

[16] EN ISO 3452-6:2008. Non-destructive testing - Penetrant testing - Part 6: Penetrant testing at temperatures lower than $100 \mathrm{C}$.

[17] PN-EN ISO 3059:2005. Badania nieniszczące. Badania penetracyjne i badania magnetyczno-proszkowe. Warunki obserwacji

[18] PN-EN ISO 12706:2003. Badania nieniszczące - Terminologia - Terminy stosowane $w$ badaniach penetracyjnych.

[19] PN-EN ISO 23277: 2006. Badania nieniszczace spoin - Badania penetracyjne spoin - Poziomy akceptacji.

[20] PN-EN ISO 9934-1: 2005. Badania nieniszczące - Badania magnetyczno-proszkowe. Część 1: Zasady ogólne.

[21] PN-EN ISO 9934-2:2003. Badania nieniszczące - Badania magnetyczno-proszkowe. Część 2: Środki wykrywające.

[22] PN-EN ISO 9934-3:2003. Badania nieniszczące - Badania magnetyczno-proszkowe. Część 3: Aparatura.

[23] PN-EN ISO 17638: 2006.Badania nieniszczące spoin - Badania magnetyczno-proszkowe spoin.

[24] PN-EN ISO 23278:2010. Badania nieniszczące spoin - Badania magnetyczno-proszkowe spoin - Poziomy akceptacji.

[25] PN-EN 1330-7: 2007. Badania nieniszczące. Terminologia. Część 7: Terminy stosowane w badaniach.

[26] PN-EN ISO 9934-2:2003. Badania nieniszczące - Badania magnetyczno-proszkowe. Część 2: Środki wykrywające.

[27] PN-EN ISO 9934-3: 2003. Badania nieniszczące - Badania magnetyczno-proszkowe. Cześć 3: Aparatura.

[28] ISO 17643:2005. Non-destructive testing of Wells-Eddy current testing of welds by complex-plane analysis. 